\title{
PENINGKATAN KESADARAN DAN KOGNITIF REMAJA DUSUN SIDOREJO RT 06 NGESTIHARJO KASIHAN BANTUL MELALUI EDUKASI KESEHATAN REPRODUKSI REMAJA DAN DAMPAK PERGAULAN BEBAS BERBASIS PEDAGOGIS
}

\author{
Anindita Imam Basri ${ }^{1}$, Ari Prasetyo ${ }^{1}$, Yuliani Dwi Astiti ${ }^{1}$, Valsa Ayunda Tisya ${ }^{1 *}$ \\ ${ }^{1}$ Universitas PGRI Yogyakarta, Yogyakarta, Indonesia \\ *valsayundatisya@gmail.com
}

\begin{abstract}
Abstrak: Kasus kesehatan reproduksi yang paling banyak terjadi di Indonesia adalah kasus seks pra-menikah yaitu sebesar $15-20 \%$ dari total remaja. Di Yogyakarta khususnya, tercatat peningkatan kasus kehamilan di luar nikah mencapai 462 kasus. Selain itu, pengajuan dispensasi pernikahan dini juga meningkat menjadi 494 permohonan dari jumlah pengajuan dispensasi tahun sebelumnya yaitu sebesar 271 permohonan. Hal ini dikarenakan masih minimnya pengetahuan remaja mengenai kesehatan reproduksi. Oleh karena itu, edukasi terkait makna dan peran penting kesehatan reproduksi terhadap remaja sangat diperlukan terutama bagi wilayah pedesaan yang memiliki keterbatasan akses informasi. Pengabdian kepada masyarakat ini bertujuan untuk memberikan edukasi kepada remaja tentang kesehatan reproduksi dan dampak pergaulan bebas sebagai upaya preventif munculnya permasalahan kesehatan reproduksi di kalangan remaja. Target pengabdian kepada masyarakat ini adalah remaja di Dusun Sidorejo RT 06, Ngestiharjo, Kasihan, Bantul. Metode yang digunakan dalam pengabdian ini adalah observasi, wawancara, focus group discussion, penyuluhan, diskusi, dan tanya jawab. Hasil kegiatan ini menunjukkan adanya peningkatan kesadaran dan kognitif para remaja terkait pentingnya kesehatan reproduksi. Selain itu, pengetahuan dan pemahaman tentang dampak pergaulan bebas juga meningkat secara signifikan. Ini menunjukkan bahwa edukasi melalui program pengabdian kepada masyarakat ini efektif dalam membangun pengetahuan dan kesadaran remaja terhadap kesehatan reproduksi dan dampak pergaulan bebas.
\end{abstract}

Kata Kunci: edukasi, kesehatan reproduksi, pergaulan bebas, remaja

\begin{abstract}
The most cases of reproductive health that occur in Indonesia are cases of premarital sex, which is 15-20\% of the total adolescents. Particularly in Yogyakarta, there was an increase in cases of pregnancies outside of marriage reaching 462 cases. In addition, the application for dispensation for early marriage also increased to 494 applications from the previous year which was 271 applications. This is due to the lack of knowledge of adolescents about reproductive health. Therefore, education related to the meaning and important role of reproductive health for adolescents is very necessary, especially for rural areas that have limited access to information. This community service program aims to provide education to adolescents about reproductive health and the impact of promiscuity as a preventive measure for the emergence of reproductive health problems among adolescents. The target of this program is youth in Sidorejo Hamlet RT 06, Ngestiharjo, Kasihan, Bantul. The methods used in this community service were observation, interview, focus group discussion, counseling, discussion, and question and answer. The results of this program indicate an increase in awareness and cognitive of adolescents regarding the importance of reproductive health. In addition, knowledge and understanding of the impact of promiscuity also increased significantly. This shows that education through this program is effective in building adolescent knowledge and awareness of reproductive health and the impact of promiscuity.
\end{abstract}

Keywords: education, reproductive health, promiscuity, adolescents

\section{Pendahuluan}

Secara etimologi, remaja berawal dari kata adolescence yang memiliki arti tumbuh menuju maturitas atau kedewasaan fisik, psikologis, dan sosial (Sarwono, 2012). Masa remaja 
merupakan tahapan transisi antara masa kanak-kanak hingga dewasa dengan rentang waktu usia 12-21 tahun (Susilawati et al., 2019). Hanifah (2013) turut memaparkan argumentasi Piaget bahwa secara psikologis, remaja merupakan sebuah kurun waktu yang memposisikan individu sebagai bagian yang terlepas dari naungan orang tua, sehingga akan mulai beradaptasi dan bersinergi dengan sekelompok masyarakat dewasa dan menduduki derajat yang sama. Fase remaja merupakan sebuah proses yang riskan bagi para kalangan remaja, karena menghadapi adaptasi yang cukup besar, pertumbuhan fisik dan proses maturitas, sehingga fase ini menjadi sebuah proses kehidupan yang vital dan penentu kehidupan masa depan bagi setiap remaja.

Secara implisit, proporsi kalangan remaja di Indonesia secara kuantitas memiliki kontribusi yang cukup besar. Berdasarkan Badan Pusat Statistik (2020), total keseluruhan penduduk di Indonesia tercatat sejumlah 268.074 .600 orang, sedangkan porsi kuantitas remaja mencapai 67.268 .900 orang atau dapat dikatakan sebesar 25,09\% dari jumlah penduduk Indonesia secara komprehensif. Tingginya jumlah penduduk remaja ini juga menjadi sebuah refleksi bahwa remaja memegang peran vital dalam menentukan kualitas dan daya saing bangsa, sehingga segala aspek yang mempengaruhi kualitas remaja sangat perlu diperhatikan.

Kalangan remaja memegang peran vital dalam kontinuitas ketersediaan sumber daya manusia Indonesia yang unggul. Dengan kata lain, kalangan remaja menentukan prospek kehidupan bangsa ke depan. Terlebih lagi remaja memiliki berbagai jenis potensi, yaitu antara lain: 1) Potensi Spiritual, 2) Potensi Intelektual, 3) Potensi Emosional, 4) Potensi Fisikal (BAPPENAS, 2010). Berkaitan dengan potensi fisikal dan penunjang potensi lainnya, maka remaja perlu memiliki kualitas kesehatan yang baik. Salah satu bidang kesehatan yang patut diperhatikan remaja yaitu kesehatan reproduksi. Kesehatan reproduksi adalah suatu keutuhan dari kesejahteraan jasmani, psikis, dan sosial, yang tidak hanya terlepas dari suatu penyakit atau ketidaknormalan fisik dalam hal reproduksi (Yarza et al., 2019). Dengan kata lain, pada hakikatnya kesehatan reproduksi tidak hanya mencakup kesejahteraan secara fisik, melainkan kesejahteraan psikologis. Namun, apabila remaja masih minim akan pengetahuan dan kesadaran terkait kesehatan reproduksi, maka akan muncul berbagai kasus kesehatan reproduksi remaja. Permasalahan tersebut dapat berupa penyimpangan perilaku remaja, seperti seks pra nikah, hamil saat usia dini sehingga putus sekolah, aborsi, HIV/AIDS, maupun penyakit menular seksual (Ernawati, 2018).

Tahun 2016, World Health Organization (WHO) menemukan bahwa di Yaman, Nepal, India, negara-negara Karibia dan Eropa, serta sepuluh negara Amerika Latin, kasus hubungan seksual remaja telah mencapai lebih dari $21 \%$ atau sama dengan seperlima dari total remaja dan presentase kasus remaja laki-laki dalam hubungan seksual lebih tinggi daripada remaja perempuan yaitu sebesar $24 \%$. Kasus hamil di luar nikah dan aborsi sebelum berusia 20 tahun pun tercatat sebesar 5,7\% dari natalitas (Inchley \& Currie, 2014). Di Indonesia, sebesar 15$20 \%$ dari total remaja sudah pernah berhubungan seks pra-menikah dan terdapat 15 juta remaja perempuan yang telah melahirkan setiap tahunnya (Yusfarani, 2020). Survei lain menunjukkan bahwa $2 \%$ remaja perempuan dan $8 \%$ remaja laki-laki telah melakukan seks 
sebelum nikah. Remaja perempuan berusia 15-19 tahun telah hamil di luar nikah sebesar $16 \%$. Remaja sebesar $19 \%$ laki-laki dan $23 \%$ perempuan mengetahui tindakan aborsi yang dilakukan oleh teman-temannya, dan di antara mereka sebesar $1 \%$ telah mendampingi aborsi tersebut (Baroroh, 2021). Selain itu, perilaku seks di luar nikah juga menyebabkan kasus HIV pada remaja berusia 15-19 tahun sebesar 3,6\% kasus dan AIDS sebesar 2,1\% kasus, serta jumlah orang yang meninggal yaitu sebesar 1,08\% kasus. Simanjuntak (2020) memaparkan bahwa seks bebas oleh remaja di bawah usia 17 tahun akan meningkatkan peluang kanker serviks hingga lebih dari 10 kali lipat.

Salah satu wilayah yang cukup rentan terhadap permasalahan kesehatan reproduksi remaja, yaitu wilayah Yogyakarta. Pada tahun 2020, ditemukan sebesar 462 kasus kehamilan tidak diinginkan di luar nikah. Selain itu, Dinas Pemberdayaan Perempuan Perlindungan Anak dan Pengendalian penduduk (DP3AP2) DIY mencatat adanya lonjakan pengajuan dispensasi pernikahan usia dini yang sangat signifikan, yaitu menjadi 494 pengajuan dispensasi. Angka ini meningkat drastis dari jumlah kasus sebelumnya yaitu hanya sebesr 271 pengajuan. Mayoritas pengajuan dispensasi menikah tersebut dikarenakan faktor kehamilan yang terjadi di luar nikah (Winduajie, 2021). Sebuah studi lain menyatakan bahwa faktor penyebab terjadinya seks di luar nikah yang paling sering diutarakan yaitu $57,7 \%$ remaja laki-laki memiliki rasa ingin tahu yang tinggi, 38\% remaja perempuan mengatakan bahwa hal tersebut terjadi tanpa direncanakan, dan 12,6\% remaja perempuan mengakui bahwa adanya pemaksaaan hubungan seksual oleh pasangannya (SDKI, 2012).

Berbagai kasus tersebut berkonsentris terhadap pentingnya edukasi mengenai kesehatan reproduksi bagi kalangan remaja. Pada dasarnya, atensi terhadap pentingnya layanan kesehatan reproduksi berawal dari diadakannya International Conference on Population and Development (ICPD) di Kairo pada tahun 1994 (Situmorang, 2011). Hasil konsensus tersebut sepakat bahwa perlu adanya pelayanan kesehatan reproduksi dan informasi yang bermutu dan tidak diskriminatif. Namun, hingga saat ini kesepakatan yang telah dimasukkan dalam Millenium Development Goals (MDGs) dan upaya pengintregrasian program layanan kesehatan dasar di setiap puskemas ternyata masih tidak terealisasi dengan baik.

Berbagai permasalahan kesehatan reproduksi remaja masih bermunculan. Banyak kalangan masyarakat yang menganggap bahwa ilmu mengenai kesehatan reproduksi remaja adalah suatu hal bersifat tabu atau kurang pantas untuk diberitahukan ataupun didiskusikan, bahkan dari petugas kesehatan, guru, ataupun orang tua yang memiliki peran penting masing-masing. Hal ini sesuai dengan fenomena yang jarang disadari di kalangan masyarakat, yaitu banyak kalangan remaja yang merasa malu menanyakan sesuatu terkait reproduksi kepada orang tuanya, karena menganggap hal tersebut tabu (Emilda, 2021). Faktor inilah yang dapat semakin meningkatkan maraknya kasus kesehatan reproduksi remaja.

Bertolak dari pemaparan urgensi dan faktor pemicu permasalahan kesehatan reproduksi, dapat ditarik kesimpulan bahwa kalangan remaja membutuhkan pengetahuan terkait kesehatan reproduksi (Astuti et al., 2021). Edukasi kesehatan reproduksi remaja ini penting sebagai sebuah upaya pemberdayaan ataupun peningkatan kesejahteraan remaja. 
Hal ini berkaitan dengan jati diri remaja sebagai aktor yang menentukan kesejahteraan negara di masa mendatang dan remaja perlu dipersiapkan agar dapat memberikan implikasi yang positif pada saat mengalami bonus demografi (Baroroh, 2021). Kesalahan informasi dapat menyebabkan remaja menjadi salah persepsi dan pengetahuan, sehingga justru dapat menyesatkan remaja untuk perilaku free sex, aborsi, hamil sebelum menikah dan terkena penyakit HIV (Udu \& Wiradirani, 2014). Melalui pendidikan kesehatan reproduksi, maka remaja akan lebih mudah mengenali dan memahami mengenai seksualitas, khususnya perilaku seks berisiko.

Berdasarkan hasil survei di Dusun Sidorejo RT 06 Ngestiharjo, Kasihan, Bantul, permasalahan yang ditemui adalah minimnya pengetahuan kalangan remaja terkait kesehatan reproduksi di Dusun Sidorejo RT 06 Ngestiharjo. Banyak remaja yang belum mengetahui definisi kesehatan reproduksi yang sebenarnya. Sebagian besar hanya menganggap bahwa kesehatan reproduksi berkaitan dengan fisik, sedangkan pada realitanya kesehatan reproduksi juga berkaitan dengan psikologis remaja. Solusi yang ditawarkan yaitu berupa penyuluhan kesehatan berupa sosialisasi makna dan pentingnya kesehatan reproduksi remaja, serta edukasi mengenai dampak pergaulan bebas. Sasaran dari program pengabdian masyarakat adalah perkumpulan remaja karang taruna Dusun Sidorejo RT 06 Ngestiharjo Kasihan Bantul yang dianggap sebagai sumber aset berpotensial yang diharapkan menjadi salah satu sumber daya yang berkualitas dan berdaya saing unggul.

Tujuan pengabdian kepada masyarakat ini adalah untuk meningkatkan kognitif para remaja Dusun Sidorejo RT 06 mengenai makna kesehatan reproduksi, sehingga membentuk mindset, pola pikir, dan sikap yang tepat. Kedua, untuk meningkatkan pengetahuan mengenai berbagai permasalahan kesehatan reproduksi, baik secara fisik maupun psikologis. Ketiga, untuk mencegah atau meminimalisasi dampak permasalahan kesehatan reproduksi, terutama mengenai seks bebas. Selain itu, kegiatan pengabdian ini bertujuan agar para remaja dapat mengambil tindakan korektif dan bijaksana. Adapun manfaat dari realisasi kegiatan pengabdian masyarakat ini, yaitu para remaja terhindar dari berbagai kesalahan persepsi mengenai arti kesehatan reproduksi. Di samping itu, para remaja Dusun Sidorejo RT 06 juga dapat memiliki ilmu dan wawasan dalam hal kesehatan reproduksi, sehingga mampu mencegah terjadinya masalah-masalah yang berkaitan dengan kesehatan reproduksi.

\section{Metode}

Tindaklanjut dari identifikasi solusi yang ditawarkan atas permasalahan yaitu edukasi kesehatan reproduksi sebagai aktualisasi tindakan untuk mencegah perilaku seks bebas di kalangan remaja. Kegiatan pengabdian masyarakat ditujukan untuk target atau sasaran pengabdian yaitu remaja Dusun Sidorejo RT 06 Ngestiharjo Kasihan Bantul di Dusun Sidorejo RT 06 Ngestiharjo Kasihan Bantul. Pengabdian masyarakat dilakukan melalui upaya sosialisasi kepada para remaja dengan berbagai bahan pertimbangan yang ada dan disesuaikan dengan identifikasi dan analisis permasalahan mengenai desa secara keseluruhan dan mitra secara aktual. Metode pengabdian yang ditempuh dalam kegiatan ini adalah Participatory Rural 
Appraisal (PRA) atau Pendekatan Partisipatif Kondisi Pedesaan (Farisia et al., 2021). Pendekatan ini dtujukan untuk memahami kondisi wilayah yang bersangkutan secara detail agar pengabdi mampu memperoleh pengalaman, pengetahuan, dan gagasan warga desa (Matahari et al., 2021). Metode Participatory Rural Appraisal ini efektif karena menggunakan metode learning and sharing yang memperkenankan setiap peserta saling bertukar informasi dalam menganalisis permasalahan untuk diidentifikasi perencanaan dan tindak lanjut. Selain itu, detail metode konseptual program pengabdian masyarakat telah diilustrasikan pada Gambar 1, baik dari observasi hingga penentuan output berupa target luaran yang diharapkan.

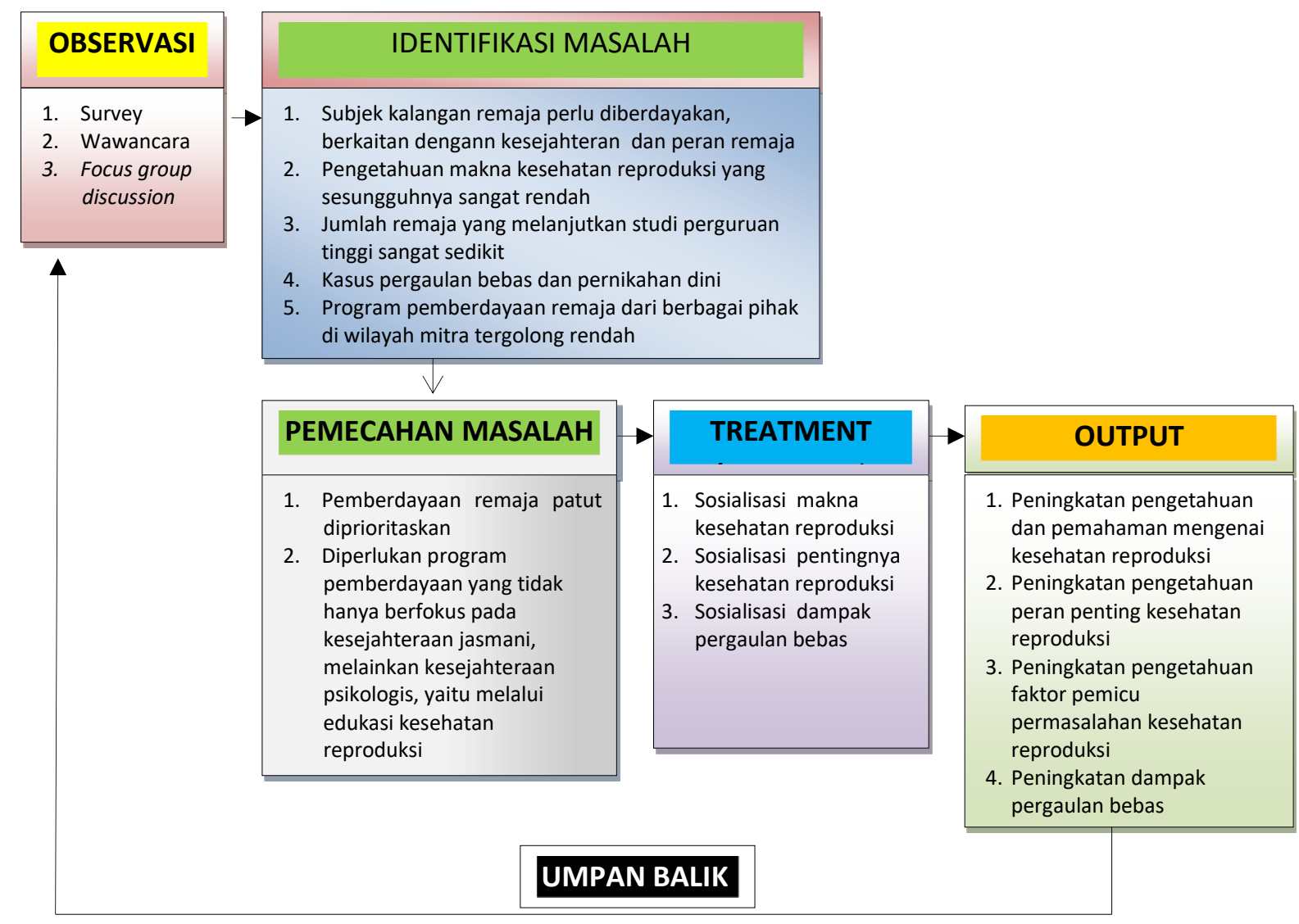

Gambar 1. Bagan Kerangka Konseptual Program Pengabdian Masyarakat

Program pemberdayaan masyarakat ini juga melalui beberapa tahapan yang terstruktur. Tahap kegiatan pengabdian masyarakat disusun mulai dari tahap persiapan, pelaksanaan, evaluasi program, sampai pada tahap pelaporan. Hal ini secara ringkas dapat dilihat pada Tabel 1 yang menunjukkan alur kegiatan pengabdian masyarakat.

Adapun metode pelaksanaan kegiatan pengabdian masyarakat yang digunakan, yaitu: 1) Pendekatan pedagogik, sebagai metode pendekatan dengan mitra yang bersifat mendidik, 2) Penyuluhan, digunakan untuk menyampaikan pengetahuan dan wawasan secara umum dan khusus tentang makna dan peran penting kesehatan reproduksi, 3) Tanya jawab, ditujukan untuk menjawab kurangnya pemahaman atau mengkonfirmasi atas suatu kebenaran informasi. Untuk evaluasi program, pengabdi menggunakan instrumen kuesioner 
yang dibagikan kepada seluruh peserta sebelum dan setelah kegiatan dilaksanakan. Hal ini ditujukan untuk mengukur dan membandingkan tingkat pengetahuan dan pemahaman peserta antara sebelum dan sesudah edukasi diberikan. Indikator keberhasilan dalam pelaksanaan kegiatan pengabdian masyarakat ini, yaitu adanya peningkatan persentase pengetahuan dan pemahaman di setiap indikator minimal $25 \%$. Nilai persentase evaluasi program dihitung berdasarkan jumlah peserta $(n)$.

Tabel 1. Alur Kegiatan Pengabdian Masyarakat

\begin{tabular}{|c|c|}
\hline \multicolumn{2}{|r|}{ Tahap Persiapan } \\
\hline Pra-Survei & $\begin{array}{l}\text { Identifikasi permasalahan \& kebutuhan mitra melalui observasi, } \\
\text { wawancara, dan focus group disussion }\end{array}$ \\
\hline Pembentukan Tim PKM & $\begin{array}{l}\text { Pembentukan Tim untuk } \\
\text { Menemukan solusi bagi mitra }\end{array}$ \\
\hline Pembuatan Proposal & $\begin{array}{l}\text { Proposal ditujukan sebagai hasil luaran dari pembentukan tim } \\
\text { dan untuk sarana akomodasi dana untuk pelaksanaan kegiatan }\end{array}$ \\
\hline Koordinasi Tim \& Mitra & $\begin{array}{l}\text { Merinci dan merncanakan jadwal, tahapan acara, tugas serta } \\
\text { tanggung jawab setiap pengurus kegiatan }\end{array}$ \\
\hline Persiapan Materi & Pembuatan materi sosialisasi \\
\hline \multicolumn{2}{|r|}{ Tahap Pelaksanaan } \\
\hline $\begin{array}{l}\text { Sosialisasi kesehatan } \\
\text { reproduksi dan dampak } \\
\text { pergaulan bebas }\end{array}$ & $\begin{array}{l}\text { Kegiatan dilaksanakan melalui pemaparan materi dan diskusi ( } 90 \\
\text { menit) }\end{array}$ \\
\hline Tanya jawab dan diskusi & Kegiatan dilaksanakan setelah pemaparan materi (20 menit) \\
\hline \multicolumn{2}{|r|}{ Evaluasi Program } \\
\hline \multicolumn{2}{|c|}{$\begin{array}{c}\text { Hal ini ditunjukkan melalui hasil perhitungan tingkat pengetahuan mitra sebelum dan sesudah } \\
\text { pelaksanaan program melalui kuesioner pre-test dan post-test dengan durasi masing-masing } 10 \\
\text { menit }\end{array}$} \\
\hline \multicolumn{2}{|c|}{ Pelaporan } \\
\hline Penyusunan laporan dil & $\begin{array}{l}\text { sebagai bentuk pertanggung jawaban atas pelaksanaan program } \\
\text { untuk kemudian dilakukan publikasi }\end{array}$ \\
\hline
\end{tabular}

\section{Hasil dan Pembahasan}

Kegiatan pengabdian masyarakat dilaksanakan di salah satu rumah warga yaitu Rumah Bapak Ipung Dusun Sidorejo RT 06 Ngestiharjo Kasihan Bantul, dengan sasaran pengabdian yaitu remaja Dusun Sidorejo RT 06 Ngestiharjo Kasihan Bantul. Program realisasi pengabdian masyarakat ini dilaksanakan pada tanggal 24 Februari 2021 pada pukul 18.20 WIB. Jumlah peserta yang hadir yaitu 12 peserta yang terdiri dari remaja perkumpulan karang taruna Dusun Sidorejo RT 06 Ngestiharjo Kasihan Bantul. Penyaji adalah narasumber konselor PUSPAGA KESENGSEM Dinas P3AP2KB Kabupaten Sleman yaitu Bapak Ari Prasetyo, S.Psi.

Metode kegiatan pengabdian yang ditempuh yaitu penyuluhan melalui ceramah, diskusi, tanya jawab dan demonstrasi. Penyuluhan dipercayai sebagai metode pendekatan yang paling ampuh untuk menghasilkan peningkatan kognitif remaja dan menstimulus remaja untuk memperbaiki perilaku agar tercipta tingkat kesehatan yang mandiri (Ariyanti et al., 2019). 
Pelaksanaan pengabdian juga disertai dengan evaluasi program yang bertujuan untuk meninjau tingkat keberhasilan maupun dampak positif dari program yang dilakukan. Nilai persentase yang dihasilkan diperoleh dari jumlah peserta ( $n$ ) yang telah memenuhi indikator. Total peserta yang terlibat dalam evaluasi program sebanyak 12 peserta dan nilai persentase tiap indikator dihitung menggunakan formula $\%=\left(\frac{n}{12}\right) \times 100 \%$

Tabel 2. Tabulasi Data Hasil Pencapaian Target Luaran Sosialisasi Kesehatan Reproduksi Remaja dan Dampak Pergaulan Bebas

\begin{tabular}{llrrrr}
\hline & \multicolumn{1}{c}{ Indikator } & Pre-test & \multicolumn{2}{c}{ Post-test } \\
\cline { 3 - 6 } No. & $\mathbf{n}$ & $\mathbf{\%}$ & $\mathbf{n}$ & $\boldsymbol{\%}$ \\
\hline 1. & $\begin{array}{l}\text { Pengetahuan dan pemahaman mengenai definisi kesehatan } \\
\text { reproduksi remaja yang tepat }\end{array}$ & 2 & 16,7 & 12 & 100 \\
2. & $\begin{array}{l}\text { Pengetahuan dan pemahaman mengenai peran pentingnya } \\
\text { kesehatan reproduksi remaja }\end{array}$ & 1 & 8,3 & 12 & 100 \\
3. $\quad \begin{array}{l}\text { Pengetahuan dan pemahaman mengenai berbagai jenis } \\
\text { masalah kesehatan reproduksi remaja }\end{array}$ & 6 & 50 & 11 & 91,7 \\
4. $\quad \begin{array}{l}\text { Pengetahuan dan pemahaman mengenai faktor pemicu } \\
\text { permasalahan kesehatan reproduksi remaja }\end{array}$ & 3 & 25 & 12 & 100 \\
5. & $\begin{array}{l}\text { Pengetahuan dan pemahaman mengenai dampak } \\
\text { pergaulan bebas }\end{array}$ & 7 & 58,3 & 12 & 100 \\
\hline
\end{tabular}

Berdasarkan hasil evaluasi program pada Tabel 2 tersebut dapat dikatakan bahwa pengetahuan dan pemahaman para peserta tentang definisi kesehatan reproduksi masih sangat kurang yaitu hanya sebesar $16,7 \%$ atau sebanyak dua peserta yang memahami hal tersebut. Mayoritas para peserta masih memiliki stereotip bahwa kesehatan reproduksi hanya seputar perubahan primer atau perubahan secara biologis. Peserta diberikan pemahaman dan wawasan bahwa kesehatan reproduksi remaja mencakup kesejahteraan fisik, psikis, dan sosial, yang tidak semata-mata berkaitan dengan penyakit atau keabnormalan reproduksi (Yarza et al., 2019). Perilaku remaja dalam masa tahapan menuju maturitas secara fisik dan psikis juga merupakan salah satu aspek dari kesehatan reproduksi remaja. Oleh karena itu, sangat penting bagi remaja Dusun Sidorejo RT 06 Ngestiharjo untuk mengetahui makna kesehatan reproduksi secara tepat yang diikuti dengan pemahaman seutuhnya bahwa aspek psikologis atau keperilakuan termasuk dalam kesehatan reproduksi remaja. Setelah diadakan sosialisasi, remaja Dusun Sidorejo RT 06 Ngestiharjo Kasihan Bantul sebesar 100\% atau seluruh peserta yang berjumlah 12 orang telah berhasil memahami makna kesehatan reproduksi remaja dengan tepat.

Kegiatan pengabdian masyarakat ini berfokus terhadap upaya pemberdayaan kalangan remaja sebagai generasi penerus bangsa. Hal ini sejalan dengan penelitian Syam et al. (2021) yang telah membuktikan bahwa edukasi kesehatan reproduksi akan meningkatkan pengetahuan remaja secara signfikan. Semakin tinggi tingkat pengetahuan remaja, maka semakin tinggi pula taraf pemberdayaan yang diperoleh. Di sisi lain, edukasi seperti ini sangat penting untuk mematahkan paradigma tradisional bahwa kesehatan reproduksi remaja 
merupakan suatu hal yang tabu untuk didiskusikan, sebab justru remaja sangat membutuhkan ilmu dan wawasan ini agar dapat mengetahui cara menjaga kesehatan reproduksi ataupun dalam berperilaku. Hal ini sesuai dengan pemaparan Kurniawan \& Maryanti (2019), bahwa walaupun tidak sedikit remaja yang telah mengenal seks, namun banyak yang menganggap bahwa obrolan seks merupakan hal yang tabu. Pemateri juga menyampaikan terkait studi empiris yang relevan bahwa dominan remaja justru tidak menanyakan kesehatan reproduksi kepada orang tuanya, melainkan kepada temannya (Nurmansyah et al., 2013).

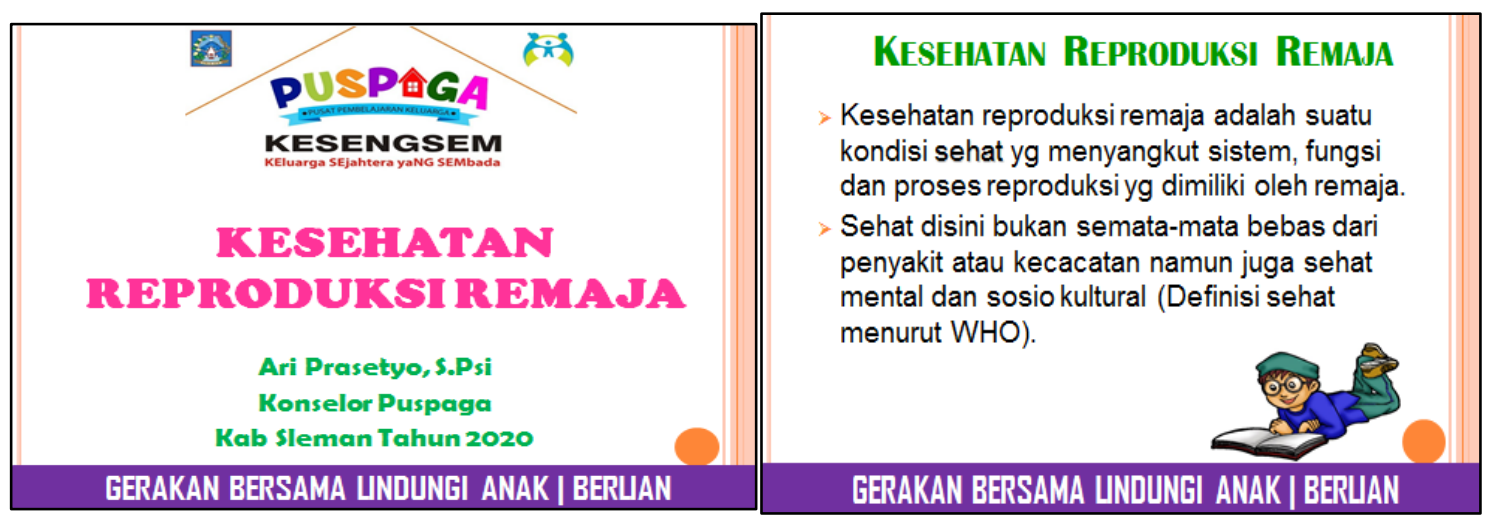

Gambar 2. Contoh Materi Powerpoint Edukasi Kesehatan Reproduksi Remaja dan Dampak Pergaulan Bebas

Di samping itu, remaja sangat perlu mengetahui peran pentingnya pengetahuan kesehatan reproduksi remaja. Namun, hasil evaluasi program sosialisasi menunjukkan bahwa hanya sebesar $8,3 \%$ atau satu peserta yang mengetahui pentingnya pengetahuan kesehatan reproduksi. Kasus tersebut relevan dengan penelitian Permatasari dan Suprayitno (2021) yang juga membuktikan bahwa pengetahuan kesehatan reproduksi di kalangan para remaja di Desa Nambakor masih rendah, yaitu 55,7\% atau sejumlah 29 remaja. Hal tersebut dikarenakan keterbatasan akses informasi yang diterima dan kualitas tenaga kesehatan setempat yang rendah. Dengan kata lain, edukasi ini sangat cocok dengan kebutuhan remaja di Dusun Sidorejo RT.06, bahwa sangat penting untuk memberikan informasi terkait kesehatan reproduksi remaja sejak usia dini sebagai upaya preventif timbulnya permasalahan lain (Sari \& Dahlia, 2021).

Pada saat sosialisasi berlangsung, pemateri juga memberikan pertanyaan spontanitas untuk membangun komunikasi yang interaktif, terdapat satu peserta yang menjawab bahwa pengetahuan kesehatan reproduksi remaja penting hanya semata untuk mempunyai keturunan dan penerus keluarga. Remaja Dusun Sidorejo tidak menyadari bahwa pengetahuan kesehatan reproduksi dapat mencegah terjadinya kasus asusila dan pergaulan bebas. Pengetahuan kesehatan reproduksi sangat berperan vital dikarenakan dapat mencegah perilaku pra nikah, hamil di luar nikah, HIV ataupun aborsi (Udu \& Wiradirani, 2014). Selain itu, wawasan mengenai perilaku seksual yang benar dapat membentuk rasa tangggung jawab dan cara membuat keputusan penting dalam hal seksualitas, serta mampu mencegah remaja dari perilaku seksual yang irasional (Ardiyanti \& Muti'ah, 2013). Hal ini sangat sesuai dengan penelitian Astuti et al. (2021) bahwa ditemukannya pengaruh signifikan antara pendidikan kesehatan reproduksi remaja dan perilaku seksual remaja. Setelah sosialisasi, keseluruhan 
peserta yaitu 12 peserta atau sebesar 100\% telah berhasil menyerap pengetahuan dan pemahaman mengenai peran pentingnya kesehatan reproduksi remaja. Edukasi seksual bersifat sangat kompleks, tidak hanya menanamkan pemahaman mengenai masalah seks ataupun bahaya seks, akan tetapi hakikatnya edukasi seks juga berkonsentris pada upaya penanaman moralitas seksual remaja (Kurniawan \& Maryanti, 2019).
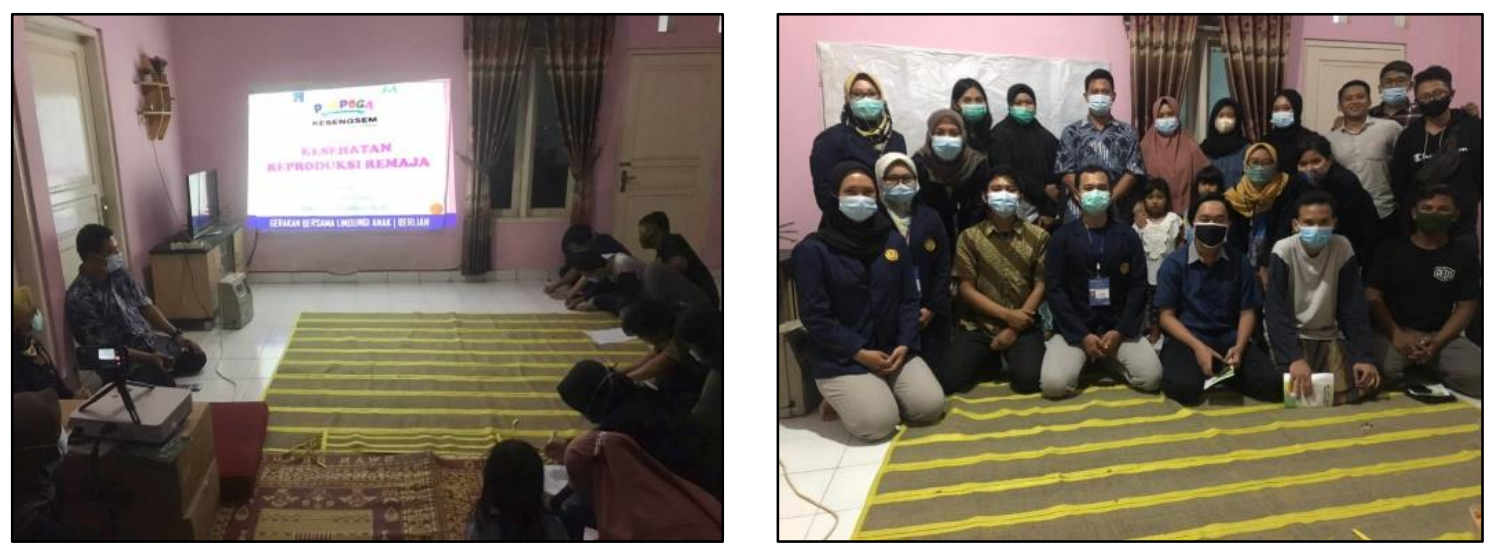

Gambar 3. Pelaksanaan Sosialisasi Kesehatan Reproduksi Remaja dan Dampak Pergaulan Bebas

Para peserta juga diberikan pengetahuan mengenai berbagai macam jenis permasalahan kesehatan reproduksi remaja, seperti keputihan, chlamydia, kanker serviks, penyakit gonorrhea, HIV/AIDS atau penyakit seksual menular lainnya. Selain itu, peserta diberikan penjelasan contoh permasalahan kesehatan reproduksi remaja lainnya dari perspektif keperilakuan remaja, yaitu antara lain: seks bebas di luar nikah, hamil di usia dini, aborsi, penggunaan alat pengaman serta berhubungan intim pra nikah, konsumsi obat-obat terlarang, kekerasan seksual (Ernawati, 2018). Awalnya, hanya sebesar 6 peserta atau 50\% peserta yang mengetahui mengenai macam-macam permasalahan kesehatan reproduksi remaja, setelah dilakukan post-test diperoleh hasil bahwa $100 \%$ telah berhasil memahami materi yang disampaikan.

Menurut penelitian terdahulu oleh Simanjuntak (2020), setengah responden siswa dari SMK Negeri 1 Kabanja sama sekali belum memperoleh informasi terkait perilaku seks berisiko dan para responden menilai bahwa berpelukan dan berciuman adalah hal yang wajar, artinya para siswa tersebut tidak mengetahui bahwa perilaku tersebut termasuk perilaku seks berisiko yang dapat menimbulkan perilaku seks bebas. Hal ini dikarenakan adanya sebuah implikasi negatif dari arus globalisasi yang mempengaruhi psikologis remaja. Kini, banyak remaja yang lebih mementingkan penampilan fisik saja dibandingkan dengan kesehatan alat reproduksi yang sebenarnya memberikan dampak di masa depan (Kurniawan \& Maryanti, 2020).

Permasalahan keempat, hanya sebesar 3 peserta atau $25 \%$ peserta yang mengetahui faktor penyebab permasalahan kesehatan reproduksi remaja. Faktor tersebut diantaranya adalah minimnya informasi dan pelayanan kesehatan reproduksi yang sampia saat ini belum terpenuhi secara optimal. Faktor pemicu lainnya dari kasus penyimpangan seksual remaja yaitu remaja cenderung mencari informasi sendiri, baik melalui teman ataupun media massa yang kebenarannya tidak dapat terjamin. Rawannya permasalahan kesehatan reproduksi remaja dan 
segala konsekuensinya juga dipengaruhi oleh adanya perubahan fisik dan hormon remaja yang memicu adanya sebuah dorongan atau motivasi seksual remaja (Eka, 2017). Selain itu, rendahnya pengetahuan remaja mengenai kesehatan reproduksi, minimnya pemaparan mengenai cara menjaga kesehatan reproduksi dan akses informasi yang sering diperoleh dari media sosial merupakan faktor pendorong maraknya kasus kesehatan reproduksi remaja.

Rendahnya pengetahuan remaja terkait pengetahuan kesehatan reproduksi disebabkan oleh beberapa faktor, yaitu: 1) Pendidikan formal. 2) Ketersediaan informasi, baik dari orang tua, petugas kesehatan, guru maupun media massa (Asiah, 2016). Berdasarkan hasil observasi, tingkat pendidikan formal di Dusun Sidorejo RT 06 Ngestiharjo Kasihan Bantul tergolong masih rendah, sehingga tingkat pengetahuan remaja mengenai kesehatan reproduksi rendah dan dapat memicu timbulnya berbagai kasus permasalahan kesehatan reproduksi remaja. Kurangnya informasi maupun program pemberdayaan juga dapat menjadi salah satu faktor minimnya pengetahuan kesehatan reproduksi di Dusun Sidorejo RT 06 Ngestiharjo. Ketidakbenaran informasi yang diinterpretasikan dapat menyebabkan individu menjadi salah mengartikan atau memahami terkait pengetahuan dan persepsi kesehatan reproduksi. Selain itu, faktor pemicu permasalahan kesehatan reproduksi lainnya seperti pernikahan usia dini dikarenakan pergaulan bebas, pemaksaan orang tua, pendidikan rendah, keingintahuan mengenai seks, lingkungan, dan ekonomi (Oktavia et al., 2018). Sebesar 100\% atau 12 peserta akhirnya mampu memahami faktor-faktor penyebab berbagai kasus kesehatan reproduksi, sehingga diharapkan para remaja dapat lebih mawas diri.

Di sisi lain, sebelum mengikuti sosialisasi diperoleh hasil sebesar 7 peserta atau 58,3\% peserta telah mengetahui dampak pergaulan bebas. Menurut Sari \& Dahlia (2021), pergaulan bebas dapat menyebabkan kehamilan tidak diinginkan, aborsi, penyakit menular seksual, pemerkosaan, pelecehan seksual, pelacuran, dan penyimpangan-penyimpangan seksual lainnya. Terlebih lagi, kehamilan yang tidak diinginkan menyebabkan kasus kematian sebesar 75\% (Rahayu et al., 2021). Selain itu, bagi kalangan remaja perempuan yang berusia di bawah 20 tahun akan mengakibatkan aborsi yang tidak aman, sekaligus beresiko kecacatan, kemandulan bahkan kematian (Dumilah, 2019). Peserta juga diberikan pemahaman bahwa pergaulan bebas sebelum menikah secara psikologis dapat menyebabkan implikasi negatif seperti rasa cemas, takut, merasa bersalah dan berdosa, depresi, sedangkan dampak sosialnya dapat berupa pengucilan, cemoohan, hamil sebelum nikah sehingga putus sekolah, dan berbagai sanksi sosial dari masyarakat. Pergaulan bebas juga menyebabkan dampak negatif dari segi ekonomi, yaitu pengadaan biaya perawatan selama kehamilan hingga setelah melahirkan, serta hilangnya sensitivitas dengan Tuhan juga merupakan dampak negatif pergaulan bebas secara spiritual (Maryati et al., 2012).

Berdasarkan hasil sosialisasi kesehatan reproduksi remaja dan dampak pergaulan bebas, diperoleh hasil pencapaian menurut perbandingan pengisian kuesioner sebelum dan sesudah dilakukannya sosialisasi, yaitu menunjukkan adanya perubahan positif dan peningkatan yang signifikan dari setiap indikator, sehingga dapat disimpulkan bahwa program sosialisasi kesehatan reproduksi remaja dan dampak pergaulan bebas telah berhasil meningkatkan kualitas karang taruna Dusun Sidorejo RT 06 Ngestiharjo Kasihan Bantul. 


\section{Kesimpulan}

Kegiatan pengabdian masyarakat yang telah dilakukan di Dusun Sidorejo RT 06 Ngestiharjo Kasihan Bantul dengan target pengabdian yaitu remaja karang taruna Dusun Sidorejo RT 06 Ngestiharjo Kasihan Bantul telah berjalan dengan sukses dan lancar. Hasil evaluasi program menunjukkan adanya peningkatan kesadaran dan kognitif para remaja mengenai pentingnya kesehatan reproduksi. Selain itu, pengetahuan dan pemahaman tentang dampak pergaulan bebas juga meningkat. Peningkatan persentase pencapaian target luaran menandakan bahwa kegiatan pengabdian masyarakat telah berhasil dilaksanakan dengan hasil yang memuaskan. Secara implisit, program pemberdayaan masyarakat ini telah mampu meningkatkan kualitas remaja desa Dusun Sidorejo RT 06 Ngestiharjo dengan harapan dapat membentuk remaja yang berwawasan, mawas diri dan berperilaku hidup sehat.

\section{Ucapan Terima Kasih}

Tim pengabdi menyampaikan ucapan terimakasih kepada: 1) Pengurus wilayah Dusun Sidorejo RT 06 Ngestiharjo Kasihan Bantul yang telah mengizinkan dan memberi dukungan selama proses pelaksanaan program pengabdian ini. 2) Bapak Ipung yang telah berkenan memberikan izin kediaman beliau sebagai tempat pelaksanaan kegiatan. 3) Mitra pengabdian yaitu para remaja Dusun Sidorejo RT 06 Ngestiharjo yang telah menyambut dengan baik dan aktif dalam proses pelaksanaan program pengabdian.

\section{Referensi}

Ardiyanti, M., \& Muti'ah, T. (2013). Hubungan antara pengetahuan kesehatan reproduksi dengan perilaku seksual remaja SMA Negeri 1 Imogiri. Jurnal Spirits, 3(2), 42-49. https://doi.org/10.30738/spirits.v3i2.989

Ariyanti, K. S., Sariyani, M. D., \& Utami, L. N. (2019). Penyuluhan Kesehatan Reproduksi Remaja Untuk Meningkatkan Pengetahuan Siswa di SMP Negeri 3 Selemadeg Timur. Indonesian Journal of Community Empowerment (IJCE), 1161, 7-11.

Asiah, N. (2016). Pengaruh Penyuluhan Dalam Peningkatan Pengetahuan Kesehatan Reproduksi Remaja. Arkesmas, 1(2), 97-101.

Astuti, P. T., Rahmawati, E., \& Seftiani, M. (2021). Pengaruh Pendidikan Kesehatan Reproduksi Pada Remaja Terhadap Perilaku Sesual Remaja di Kelas XI SMK Rise Kedawung Kabupaten Cirebon. Jurnal Inovasi Penelitian, 1(10), 2025-2028. https://doi.org/10.47492/jip.v1i10.404

Badan Pusat Statistik. (2020). Hasil Sensus Penduduk 2020. https://www.bps.go.id/pressrelease/2021/01/21/1854/hasil-sensus-penduduk-2020.html

BAPPENAS. (2010). Laporan Pencapaian Tujuan pembangunan Milenium Indonesia 2010.

Baroroh, I. (2021). Upaya Peningkatan Pengetahuan tentang Pendidikan Kesehatan Reproduksi dan Seksual Pada Usia Remaja. Jurnal ABDIMAS-HIP, 2(1), 55-58. https://doi.org/10.37402/abdimaship.vol2.iss1.133

Dumilah, R. (2019). Umur, interval kehamilan, kehamilan yang diinginkan dan perilaku pemeriksaan kehamilan. Jurnal Penelitian Kesehatan Suara Forikes, 10(2), 7379. http://dx.doi.org/10.33846/sf10201

Eka, N. (2017). Pengaruh pendidikan kesehatan metode peer group terhadap pengetahuan dan sikap remaja tentang kesehatan reproduksi di SMK PGRI 1 Magetan Kelas XI (Skipsi). STIKES Bhakti Husada Mulia.

Emilda, S. (2021). Analisis Kesehatan Reproduksi Pada Remaja. Jurnal Kesehatan Dan Pembangunan, 11(21), 93-101. https://doi.org/10.52047/jkp.v11i21.104 
Ernawati, H. (2018). Pengetahuan Kesehatan Reproduksi Remaja Di Daerah Pedesaan. Indonesian Journal for Health Sciences, 2(1), 58. https://doi.org/10.24269/ijhs.v2i1.820

Farisia, H., Mohammad, A., Afandi, A., Fitriyah, R. D., \& Safriyani, R. (2021). Pendekatan_Pendekatan Dalam University Community Engagement. In UIN Sunan Ampel Press, 2021.

Hanifah, F. (2013). Hubungan Kontrol Sosial Orang Tua dengan Perilaku Seks Pranikah Remaja Kelurahan Batang Arau Kecamatan Padang Selatan. SPEKTRUM: Jurnal Pendidikan Luar Sekolah, 1(2), 1-14. https://doi.org/10.24036/spektrumpls.v1i2.2386

Inchley, J., \& Currie, D. (2014). Growing up unequal: differences in young people's gender and socioeconomic health and well-being. In Health Behavior in School-Aged Children (HBSC): International Report From the 2013/2014 Survey (Vol. 7).

Kurniawan, D. T., \& Maryanti, S. (2019). Penyuluhan Pendidikan Kesehatan Reproduksi Dan Bahaya Pornografi Untuk Anggota Palang Merah Remaja Tingkat Wira disalah satu SMA Kota Cirebon. CARADDE: Jurnal Pengabdian Kepada Masyarakat, 2(2), 145-152. https://doi.org/10.31960/caradde.v2i2.233

Maryati, I., Juniarti, N., \& Hidayat, N. (2012). Pemberdayaan Remaja Dalam Optimalisasi Kesehatan Reproduksi Remaja Di Desa Sukamandi Dan Cicadas Kecamatan Sagalaherang Kabupaten Subang. Jurnal Aplikasi Ipteks Untuk Masyarakat, 1(1), 14-19.

Matahari, R., Isni, K., \& Utami, F. P. (2021). Pemberdayaan Kesehatan Reproduksi Remaja Anggota Bina Keluarga Remaja (BKR) melalui Participatory Rural Appraisal (PRA) di Desa Potorono, Kabupaten Bantul, Daerah Istimewa Yogyakarta. Engagement: Jurnal Pengabdian Kepada Masyarakat, 5(1), 196-206. https://doi.org/10.29062/engagement.v5i1.358

Nurmansyah, M. I., Al-aufa, B., \& Amran, Y. (2013). Peran Keluarga, Masyarakat Dan Media Sebagai Sumber Informasi Kesehatan Reproduksi Pada Mahasiswa. Jurnal Kesehatan Reproduksi, 3(1), 16-23. https://doi.org/10.22435/jkr.v3i1Apr.3926.16-23

Oktavia, E. R., Agustin, F. R., Magai, N. M., \& Cahyati, W. H. (2018). Pengetahuan Risiko Pernikahan Dini pada Remaja Umur 13-19 Tahun. HIGEIA (Journal of Public Health Research and Development), 2(2), 239-248. https://doi.org/10.15294/higeia.v2i2.23031

Permatasari, D., \& Suprayitno, E. (2021). Pendidikan Kesehatan Reproduksi pada Remaja. Jurnal Empathy, 2(1), 8-12. https://doi.org/10.37341/jurnalempathy.v2i1.46

Rahayu, S., Suciawati, A., \& Indrayani, T. (2021). Pengaruh Edukasi Tentang Kesehatan Reproduksi Remaja Terhadap Pengetahuan Dan Sikap Seksual Pranikah Di Smp Yayasan Pendidikan Cisarua Bogor. Journal for Quality in Women's Health, 4(1), 1-6. https://doi.org/10.30994/jqwh.v4i1.101

Sari, C. K., \& Dahlia, I. (2021). Pendidikan Kesehatan Reproduksi Terhadap Pengetahuan Seks Bebas RemajA. Jurnal Delima Harapan, 8(1), 27-32. https://doi.org/10.31935/delima.v8i1.108

Sarwono, W. (2012). Psikologi remaja. Rajawali Pers.

SDKI. (2012). Survei Demografi Kesehatan Indonesia.

Simanjuntak, E. H. (2020). Efektivitas Penyuluhan Kesehatan Reproduksi Terhadap Pengetahuan Remaja Tentang Perilaku Seks Berisiko. Jurnal Kesehatan Mercusuar, 3(1), 46-53. https://doi.org/10.36984/jkm.v3i1.65

Situmorang, A. (2011). Pelayanan kesehatan reproduksi remaja di puskesmas: Isu dan tantangan. $\begin{array}{llll}\text { Jurnal Kependudukan } & \text { Indonesia, } & \end{array}$ http://ejurnal.kependudukan.lipi.go.id/index.php/jki/article/view/92/138

Susilawati, D., Nilakesuma, N. F., \& Surya, D. O. (2019). Penyuluhan Kesehatan Reproduksi Remaja Di SMP Pertiwi Siteba Padang. Jurnal Kreativitas Pengabdian Kepada Masyarakat, 2(2), 166-170.

Syam, N. F. S., Passe, R., \& Khatimah, H. (2021). Pengaruh Pendidikan Kesehatan Reproduksi Terhadap Tingkat Pengetahuan Tentang Perilaku Seksual Remaja Di SMA Negeri 4 Palopo. Journal of Midwifery Science and Women"s Health, 2(1), 9-14. https://doi.org/10.36082/jmswh.v2i1.419

Udu, W. S. A., \& Wiradirani, P. Y. W. (2014). Pengaruh Intervensi Penyuluhan Terhadap Pengetahuan Dan Sikap Remaja Tentang Kesehatan Reproduksi. MEDULA, 1(2), 71-75. https://doi.org/10.1037/0033-295X.104.2.344

Winduajie, Y. (2021). Permohonan Dispensasi Pernikahan Usia Dini di DI Yogyakarta Meningkat 
Transformasi: Jurnal Pengabdian Masyarakat, Vol. 17, No. 2, Desember 2021: 220-232

Selama Pandemi (Artikel web). Diakses di: https://jogja.tribunnews.com/2021/10/10/permohonan

Yarza, H. N., Maesaroh, \& Kartikawati, E. (2019). Pengetahuan Kesehatan Reproduksi Remaja Dalam Mencegah Penyimpangan Seksual. Sarwahita, 16(01), 75-79. https://doi.org/10.21009/sarwahita.161.08

Yusfarani, D. (2020). Pengetahuan Dan Sikap Mahasiswi Program Studi Pendidikan Islam Anak Usia Dini (Piaud) Tentang Kesehatan Reproduksi. Jurnal 'Aisyiyah Medika, 5(1), 21-35. https://doi.org/10.36729/jam.v5i1.307 